\title{
A TRANSFORMAÇÃO DA INFORMAÇÃO EM CONHECIMENTO PELA ESCOLA: POR UMA CONSTITUIÇÃO DOCENTE PAUTADA NA REFLEXÃO CRÍTICA
}

\section{ARTIGO ORIGINAL}

ROPPA, Janete de Lima ${ }^{1}$

ROPPA, Janete de Lima. A transformação da informação em conhecimento pela escola: Por uma constituição docente pautada na reflexão crítica. Revista Científica Multidisciplinar Núcleo do Conhecimento. Ano 05, Ed. 03, Vol. 07, pp. 119136. Março de 2020. ISSN: 2448-0959, Link de acesso: https://www.nucleodoconhecimento.com.br/educacao/transformacao-dainformacao

\section{RESUMO}

O presente artigo aborda a transformação da informação em conhecimento pela escola e pesquisa as possibilidades teórico-metodológicas que contribuem para que essa transformação aconteça, levando em consideração a escola, os docentes e o mundo do trabalho que está cada vez mais complexa e competitiva devido à globalização e às mudanças ocorridas, nos últimos anos, na economia, na tecnologia, nas relações sociais e nas relações de trabalho. A partir de uma revisão bibliográfica de teóricos que abordam esses temas, objetiva-se um entendimento acerca da formação de professores na atualidade. O resultado mostrou que apesar das dificuldades advindas do meio educacional, os docentes trabalham de forma dialética contribuindo com os alunos, futuros profissionais, buscando preparar cidadãos para a vida e para o mundo do trabalho. Os docentes trabalham para atender a demanda, oferecendo um ensino de qualidade a todos.

${ }^{1}$ Especialização Lato Sensu em Espaço Alternativo do Ensino e da Aprendizagem.

Disponível em: https://www.nucleodoconhecimento.com.br/educacao/transformacao-da- 
Palavras-chave: Função da Escola, formação de professores, mundo do trabalho.

\section{CONSIDERAÇÕES INICIAIS}

$\mathrm{Na}$ linha da educação e relações de trabalho o presente Artigo tem como objetivo analisar o papel do educador, do educando e da escola com relação o processo de Transformar a Informação em Conhecimento pela Escola no mundo contemporâneo.

A globalização trouxe o desenvolvimento tecnológico, cujo campo do conhecimento e da informação ficou "marcado" com a explosão da internet, permitindo acesso direto às pessoas e organizações do mundo inteiro. Oferecendo uma variedade de informações e serviços virtualmente interminável no mercado mundial. Conforme Vergara (2000, p. 27) "[...] é comum à ocorrência de mudanças cada vez mais difundida, persistentes e velozes. Tais mudanças dão origem a incertezas e ambiguidades que a todo o instante desafiam a capacidade de adaptação das empresas". Dessa forma requer habilidades diferenciadas e uma ensino de qualidade por parte dos sujeitos, por isso, é preciso fazer uma ruptura dos velhos valores, porque essa nova concepção influencia tanto o micro ambiente como o macro ambiente sendo preciso se adaptar à nova realidade com a necessidade de aprender continuamente e se orientar para o mercado global. (CHIAVENATO, 2003).[2]

Diante deste contexto apresenta-se o problema de pesquisa: Qual formação docente proporciona transformar informação em conhecimento na escola? O conhecimento é um fator decisivo para a vida e sobrevivência do sujeito, é por meio dele que o homem se afirmar como ser racional e vai construindo sua personalidade e se preparando para assumir seu papel na sociedade. A escola deve contribuir para a evolução do sujeito, preparando-o para vida e para a cidadania, porque o conhecimento passou a ser o requisito básico de ingresso e permanência das pessoas no mundo do trabalho. (PAIM, 1985).

O mundo do trabalho exige cada vez mais atualização, e está em constantes transformações econômica, cultural, financeira, tecnológica e humana. Com isso, as pessoas buscam adaptar-se a estas mudanças com vistas a permanecer no mundo

Disponível em: https://www.nucleodoconhecimento.com.br/educacao/transformacao-da- 
do trabalho por meio da obtenção de uma vantagem competitiva, sustentável através do conhecimento, inovações, assim como também do desenvolvimento humano.

Com o propósito de responder a questão da pesquisa buscam-se possibilidades teórico-metodológicas que contribuem para transformar informação em conhecimento na escola. Conceituar informação, conhecimentos e saberes na perspectiva do trabalho docente; diagnosticar se o conhecimento adquirido na escola contribui para formar sujeitos qualificados para atender a demanda do mundo do trabalho que está cada vez mais competitivo; relacionar a importância da formação docente para transformar informação em conhecimento, são possíveis caminhos para entender e responder a questão apresentada.

A escolha do tema justifica-se pela a questão dos princípios fundamentais da educação, a fim de formar cidadãos que atendam às necessidades sociais, e também ao mundo do trabalho, que atualmente é considerado indispensável para a sobrevivência de qualquer sujeito, porque seu conceito passa a sinalizar emergência de habilidades, atitudes e conhecimentos entre outros fatores, abrangendo associações como produtividade, legitimidade, experiência, criatividade e integração social.

O tema da pesquisa é fundamental para aqueles que buscam discutir alternativas para vencer os desafios de transformar informação em conhecimento na escola, para formar sujeitos qualificados profissionalmente para atuar no mundo do trabalho. Porque no cenário atual a educação não pode ser vista de forma isolada da área empresarial como do resto da sociedade, se o assunto interessa aos gestores, empresários, interessam também aos docentes e aos próprios profissionais na busca de sua realização pessoal, que contempla na maioria da sociedade que está à procura de profissional com habilidades diferenciada tais como comprometimento, compartilhamento das responsabilidades, confiança e ética entre outros.

Desse modo percebe-se a importância dos docentes terem conhecimento de como transformar informação em conhecimento para que possam trazer contribuições 
significativas para a vida dos educandos que vão enfrentar seu papel na sociedade, conciliando a vida pessoal com a vida profissional. Também para saber inovar e encontrar novos caminhos para o trabalho em sala de aula e para a escola.

Para os discentes é necessária conscientização dos processos educativos, e das necessidades de serem capazes de gerenciar seu estilo de vida para tornar-se, independente no meio em que vivem ou atuar como pessoas mais produtivas para realizar os objetivos tanto individuais como sociais.

Às instituições educacionais, que são o alicerce da sociedade letrada e organizada, esse estudo explica-se pela oportunidade de conhecer o processo de como transformar informação em conhecimento na escola para contribuir com o ensino aprendizagem dos alunos. Essa temática está relacionada com a necessidade de conhecimentos, tanto teórico como prático, para que possam ter capacidade de enfrentar as dificuldades que lhe serão apresentadas no contexto escolar, e para atender as necessidades de cada educando para assumir seu papel de protagonista na sociedade onde estão inseridos.

Desta forma, neste artigo faremos uma abordagem desse tema, na tentativa de compreender o processo de formação docente através de uma pesquisa bibliográfica, a partir da visão apresentada nos estudos de alguns autores como Libâneo (2008), Pimenta (2010), Tardif (2008), entre outros.

As seções que compõem este artigo estão organizadas da seguinte maneira: a primeira apresenta a introdução, com a contextualização do estudo, a delimitação do tema, à questão de estudo, os objetivos a justificativa, e a metodologia. Em seguida, o referencial teórico, o qual descreve o entendimento dos conceitos na perspectiva do trabalho docente: informação, conhecimento e saber; a escola e a formação de sujeitos para o mundo do trabalho; formação docente em tempos de grandes avanços científicos e tecnológicos. 


\section{ENTENDENDO CONCEITOS NA PERSPECTIVA DO TRABALHO DOCENTE: INFORMAÇÃO, CONHECIMENTO E SABER}

Para compreendermos os processos de desenvolvimento pessoal e profissional do professor, é preciso conhecer um conjunto de conhecimentos e saberes, que são necessários para a execução de suas atividades. Por isso é preciso entender o significado da informação, do conhecimento e do saber, que compõe sua subjetividade.

O Dicionário Aurélio (1999) traz, dentre os vários sentidos atribuídos à informação, um que diz que informação é conhecimento, participação, ou seja, quando se tem informação sobre algo é como se houvesse conhecimento, como se soubesse do que se trata. Segundo a mesma fonte complementando, "dentre os vários sentidos conhecimento é informação, notícia e ciência". (AURÉLIO, 1999, p. 529). A informação é o material direto, matéria-prima que compõe o conhecimento.

Para entender um pouco mais, buscamos referências na origem das palavras. Do Latim, "Com - junto" mais "Gnoscere - obter conhecimento, chegar, a saber,", formando então a palavra "Cognoscere - conhecer, saber".

Informação do Latim, de informare, "modelar, dar forma", surgiu à conotação de "formar uma ideia de algo", que passou depois a "descrever" e mais tarde se generalizou em "contar algo a alguém sobre alguma coisa". Segundo Altet (2001) a informação é "exterior ao sujeito e de ordem social"; o conhecimento é "integrado ao sujeito e de ordem pessoal". O saber constrói-se na interação entre conhecimento e informação, entre sujeito e ambiente, na mediação e através dela.

Porém, o conhecimento se constrói quando pensamos e refletimos diante de um fato, ou seja, quando usamos a razão e vamos além da informação. Quando sabemos investigar ou desenvolver alguma coisa, quando podemos associar o conhecimento com relação, conexão, construção, transformação, evolução, desenvolvimento das informações. 
Considerando esses fatores Libâneo afirma que:

A informação é necessária, mas por si só ela não propicia o saber. A informação é um caminho de acesso ao conhecimento, é um instrumento de aquisição de conhecimento, mas ela precisa ser analisada e interpretada pelo conhecimento, que possibilita a filtragem e a crítica da informação, de modo que ela não exerça o domínio sobre a consciência e a ação das pessoas. (LIBÂNEO, 2008, p. 49)

A informação isolada não tem significado, já o conhecimento quando processado e avaliado produz atitudes, valores e juízo moral, isto é, transforma-se em saber. Segundo Dewey (1979) é necessário que a informação seja compreendida, internalizada e reconstruída a partir de seus conhecimentos prévios.

Complementa o autor:

Quando utilizo a informação, ou seja, quando a interpreto, ligo-a a outras informações para fazer sentido ou, quando me sirvo dela para tomar uma decisão, atualizo-a. Efetuo, portanto, um ato criativo, produtivo. $\mathrm{O}$ conhecimento, por sua vez, é o fruto de uma aprendizagem, ou seja, o resultado de uma virtualização da experiência imediata. Em sentido inverso, este conhecimento pode ser aplicado, ou melhor, ser atualizado em situações diferentes daquelas da aprendizagem inicial. Toda aplicação efetiva de um saber é uma resolução inventiva de um problema, uma pequena criação. (DEWEY, 1979, p. 39)

Segundo estudos realizados por Luckesi (1996), adquirir conhecimentos não é compreender a realidade retendo informação, mas utilizando-se desta para desvendar o novo, porque quanto mais competente for o entendimento do mundo, mais satisfatória será a ação do sujeito que a detém. Por isso que informação e conhecimento não são sinônimos. De acordo com Libâneo (2008), o conhecimento é o que possibilita a liberdade intelectual e política para as pessoas darem significado à informação, isto é, julgá-la criticamente e tomar decisões mais livres e mais acertadas. 
Desta forma, a significação das palavras traz indícios de diferenças entre informação e conhecimento.

Mas, o que isso interfere na Educação? Na educação, a informação tem no professor o seu multiplicador, disseminador, propagador, o qual tem como instrumentos de sua ação o diálogo e a criatividade, mecanismos de contextualização que paulatinamente se adequam a realidade do aluno. Dessa forma, o professor no ambiente escolar é o protagonista no processo de transformar a informação em conhecimento, junto a isso, o aluno precisa localizar, selecionar, analisar, e interpretar a informação transmitida, sendo necessário sistematizar e analisar os conceitos recebidos, estabelecendo um processo permanente de revisão do conhecimento posto. (ANTUNES, 2001).

Nesse sentido, professor e aluno tem o desafio de transformar a informação em conhecimento na escola, são responsáveis por uma educação cada vez mais de qualidade que possibilitem mudanças e transformações, promovidas pelos sujeitos em sociedade. Diante disso, a informação pode-se transformar num conhecimento transformador.

De acordo com Libâneo:

O professor tem aí seu lugar, com o papel insubstituível de provimento das condições cognitivas e afetivas que ajudarão o aluno a atribuir significados às mensagens e informações recebidas das mídias, multimídias e formas diversas de intervenção educativa urbana. (LIBÂNEO, 2008, p.52)

Então, porque investigar a transformação da informação em conhecimento pela escola, porque o propósito específico da escola é de capacitar alunos a adquirir conhecimento poderoso não disponível em seu cotidiano. (YOUNG, 2007). 


\section{A ESCOLA E A FORMAÇÃO DE SUJEITOS PARA O MUNDO DO TRABALHO}

O mundo contemporâneo vem experimentando várias mudanças que estão acontecendo em escala global e uma das áreas que mais tem sofrido com essas mudanças e transformações nos últimos anos é a área econômica, ela traz grande impacto na vida social e isto reflete também na educação devido às novas medidas, leis e forma de avaliação impostas ao sistema educacional. Conforme Tedesco (1998, p. 15) "as mudanças no processo de produção, e a profunda transformação tecnológica, assim como a globalização e a competição pela conquista de mercados, estão modificando os padrões de produção e organização do trabalho".

$\mathrm{Na}$ atualidade o sistema de ensino e a escola enfrentam segundo Libâneo (2008, p. 20) várias transformações, "alteração no perfil de formação geral e profissional dos alunos, mudanças nos currículos e nas formas de gestão da escola, reavaliação das funções e responsabilidades do professorado, formas de participação das famílias etc.".

Essas são algumas das mudanças impostas às instituições educacionais e ao ambiente de trabalho que se torna cada vez mais complexo e competitivo devido à transformação social causada pela globalização.

O autor corrobora:

Essas mudanças atingem o sistema educacional, exigindo-se dele a adequação aos interesses do mercado e investimentos na formação de profissionais mais preparados para as modificações do processo de produção. Com efeito, tais modificações afetam a organização do trabalho nas empresas e o perfil de trabalhador necessário para novas formas de produção e, em consequência, os conhecimentos, habilidades e atitudes necessárias à qualificação profissional. (LIBÂNEO, 2008, p. 47) 
Para que a escola atenda a essa demanda, é fundamental que o funcionamento esteja de acordo com as caraterísticas da sociedade, proporcionando aos seus alunos o desenvolvimento de competências e preparando para o mundo do trabalho, através de um ambiente de aprendizagem de novos espaços de construção do conhecimento e do saber. [...] "a escola precisa oferecer serviços e resultados de qualidade, a fim de que os alunos que passem por ela ganhem condições de exercício e liberdade politica e intelectual". (LIBÂNEO, 2008, p.56).

Diante desta realidade, a função da escola vem mudando com o passar do tempo e as tecnologias intelectuais acompanharam essa mudança. Segundo Levi (1993) a primeira tecnologia do ensino e da aprendizagem era centrada na oralidade, a segunda na escrita, a terceira na impressão e a quarta através da tecnologia da informação e comunicação.

Hoje, a função da escola de acordo com Libâneo (2008, p.51) é a de [...] "prover formação geral básica capacidade de ler, escrever, formação cientifica, estética e ética, desenvolvimento de capacidades cognitivas e operativas". Além dessas tecnologias intelectuais, a escola também precisa se adaptar a tecnologia da informação e comunicação além das mudanças causadas pela globalização.

Para Saviani (2003, p.14) "a escola é uma instituição cujo papel consiste na socialização do saber sistematizado [...] configura-se numa situação privilegiada, a partir do qual se pode detectar a dimensão pedagógica que subsiste no interior da prática social global".

A escola contemporânea precisa voltar-se para as novas realidades, ligar-se ao mundo econômico, político e cultural. Ela precisa atender às exigências da sociedade atual, como consequência, o processo de educar tem que passar por criar contextos adequados para que as aprendizagens possam desenvolver-se. Segundo Libâneo (2008, p.51) "a escola necessária para fazer frente a essas realidades é a que provê formação cultural e científica, que possibilita o contato dos alunos com a cultura provida pela ciência, pela técnica, pela linguagem, pela estética, pela ética". 
A escola tem a missão de desenvolver a inteligência como capacidade multiforme de adaptação às diferenças e às mudanças do mundo. Tomamos por apoio, a interlocução de Perreneoud (1999, p.32) ao declarar que "a escola deve oferecer situações escolares que favoreçam a formação de esquemas de ações e de interações estáveis que possam ser transportadas para outras situações comparáveis, fora da escola ou após a escolaridade".

Segundo Libâneo (2008) as escolas para exercer seu papel na construção da democracia social e política são propostos cinco objetivos a seguir:

1. Promover o desenvolvimento de capacidades cognitivas, operativas e sociais dos alunos (processos mentais, estratégias de aprendizagem, competências do pensar, pensamento crítico), por meio dos conteúdos escolares. 2. Promover as condições para o fortalecimento da subjetividade e da identidade cultural dos alunos, incluindo o desenvolvimento da criatividade, da sensibilidade, da imaginação. 3. Preparar para o trabalho e para a sociedade tecnológica e comunicacional, implicando preparação tecnológica (saber tomar decisões, fazer analises globalizantes, interpretar informações de toda natureza, ter atitude de pesquisa, saber trabalhar junto etc.). 4. Formar para a cidadania crítica, isto é, formar um cidadão-trabalhador capaz de interferir criticamente na realidade para transformá-la e não apenas formar para integrar 0 mercado de trabalho. 5 . Desenvolver a formação para valores éticos, isto é, formação de qualidades morais, traços de caráter, atitudes, convicções humanistas e humanitárias. (LIBÂNEO, 2008, p. 53-54)

A partir desses objetivos mencionados surge então a necessidade de uma nova escola para Libâneo (2001, p. 85) [...] "a escola precisa deixar de ser meramente uma agência transmissora de informação e transforma-se num lugar de análises críticas e produção da informação, onde o conhecimento possibilita a atribuição de significados 
à informação". Assim, neste sentido, Perreoud (2000) define que o papel essencial da escola é oferecer ao educando ferramentas para dominar a vida e compreender o mundo. E o objetivo não deve ser transmitir conteúdos, mas preparar todos para a vida numa sociedade moderna.

Nessa perspectiva, o novo paradigma educacional da educação do século XXI, enfatiza segundo Perrenoud (2000) a necessidade de preparar cidadãos para a vida, no âmbito da sua totalidade, visando transformar a sociedade em mais justa, solidária e integrada, e ressalta ser essencial que as práticas pedagógicas sejam apoiadas nos quatro pilares da aprendizagem apresentados por Delors (2001, p. 101) sobre a educação ao longo da vida, "aprender a conhecer, aprender a fazer, aprender a conviver e aprender a ser".

Aprender a conhecer significa adquirir cultura geral ampla e domínio aprofundado de um reduzido número de assuntos, mostrando a necessidade de educação contínua e permanente, aprender a fazer oferecendo-se oportunidades de desenvolvimento de competências amplas para enfrentar o mundo do trabalho, aprender a conviver é cooperar com os outros em todas as atividades humanas e aprender a ser, que integra as outras três, criando-se condições que favoreçam ao sujeito a aquisição de autonomia e discernimento (ANTUNES, 2010).

O relatório da UNESCO apresenta que na prática os quatro pilares da Educação deve ser objeto de atenção igual por parte do ensino. Deve ser uma educação contextualizada que prepara o aluno para viver na sociedade, também para adaptarse constantemente a essas mudanças da sociedade, sem negligenciar as vivências, os saberes básicos e os resultados da experiência humana. A fim de que a educação apareça como uma experiência global ao longo de toda a vida, no plano cognitivo como no prático, para o sujeito enquanto pessoa e membro da sociedade. (DELORS, 2000).

Diante disso, Pimenta (1999) busca contribuir e esclarece que: 
A finalidade da educação escolar na sociedade tecnológica, multimídia e globalizadora é possibilitar que os alunos trabalhem os conhecimentos científicos e tecnológicos, desenvolvendo habilidades para operá-los, revê-los e reconstruí-los com sabedoria. O que implica analisá-los, confrontá-los, contextualizá-los. Para isso, há que os articular em totalidades que permitam aos alunos irem construindo a noção de "cidadania mundial". (PIMENTA, 1999, p.23)

Portanto a escola deve preparar intelectualmente os alunos para que possam entender e participar no mundo globalizado, pois, hoje, é parte integrante da vida da nossa sociedade. Devido a isso, a escola deve debater a educação, questionar o que está sendo feito, reforçando o aprendizado, refletir o que pode-se fazer mesmo com todos os desafios atuais para que se tenha uma educação de qualidade e que isso resulte em uma melhora na sociedade, porque o ensino é o motor da formação e transformação da sociedade.

\section{A COMPLEXIDADE NA FORMAÇÃO DOCENTE PELO MUNDO DO TRABALHO}

Vivemos em um mundo de constantes transformações, a cada nova geração mudamse as formas de se relacionar e de viver em sociedade. A "complexidade do nosso tempo, a velocidade com que as informações e o conhecimento são produzidos e as exigências para compreender e responder as questões cotidianas exige de nós atenção e um tratamento diferenciado". (OLIVEIRA, 2004, p.14).

$\mathrm{Na}$ sociedade atual com as mudanças provocadas pela globalização e pelas novas tecnologias da informação e da comunicação, os professores encontram-se frente a mais um desafio: entender como estas mudanças afetam a escola e modificam seu papel na sala de aula. Para (Tedesco, 1998), faz-se necessária à atualização constante, por isto, o maior desafio docente é ter uma formação contínua. 
Nesse sentido, os cursos de formação de professores (inicial e continuada), precisam estar voltados, para a prática reflexiva desses profissionais. Diante dessa realidade o professor precisa ser sujeito de sua própria história, mas para isso ele tem como desafio atual, segundo Nóvoa:

Valorização de paradigmas de formação que promovam a preparação de professores reflexivos, que assumam a responsabilidade do seu próprio desenvolvimento profissional e que participem como protagonistas na implementação das políticas educativas (NÓVOA, 1992, p. 27).

Candau (1996) enfatiza a importância de que a prática seja uma prática reflexiva, capaz de identificar problemas e resolvê-los e, além disso, que seja uma coletiva prática construída por todo o corpo docente da escola. Já que a prática é o centro da formação dos professores.

Nessa perspectiva de postura reflexiva, é primordial a contribuição de Perrenoud (1993) ao esclarecer que:

O profissional mobiliza um capital de saberes, de saber-fazer e de saberser que não estagnou, pelo contrário, cresce constantemente, acompanhando a experiência e, sobretudo, a reflexão sobre a experiência [...] a reflexão sobre a própria prática é, em si mesma, um motor essencial de inovação. (PERRENOUD, 1993, p.186)

Conforme Gadotti (2011, p. 50) "para o educador, não basta ser reflexivo. É preciso que ele dê sentido à reflexão". Segundo Gadotti o sentido significa dar uma direção, um caminho, isto é, propor algo no seu trabalho docente no dia-a-dia.

Essa proposta também é referendada por Nóvoa (1992) quando diz que:

[...] a formação não se constrói por acumulação (de cursos, de conhecimento ou de técnicas), mas sim através de um trabalho de 
reflexividade crítica sobre as práticas e de (re) construção permanente de uma identidade pessoal. Por isso é tão importante investir na pessoa e dar um estatuto ao saber da experiência. (NÓVOA, 1992 p.13)

De acordo com Cardoso (2002, p. 2), "a prática reflexiva é a busca de um equilíbrio entre $\mathrm{o}$ ato de rotina e $\mathrm{o}$ ato de reflexão", já que a prática deve ser pensada diariamente pelos docentes, tornando a reflexão uma constante em suas vidas.

Liberali (2010, p. 32) afirma que "[...] ao refletir criticamente, os educadores passam a ser entendidos e entenderem-se como intelectuais transformadores, responsáveis por formar cidadãos ativos e críticos dentro da comunidade". "A reflexão que permeia a concepção do professor reflexivo é uma reflexão permanente e contínua, que permite ao professor, compreender as ações por ele desenvolvidas, analisá-las e, caso seja necessário, reconstruí-las". (PERREOUND, 2002, p. 13)

Entretanto, Libâneo (2008, p.228), "escreve que, para enfrentar a complexidade do trabalho de ensinar, não basta somente à prática reflexiva como não é suficiente apenas à experiência". Nesse sentido, em sua formação docente há diversos saberes utilizado no cotidiano de seu trabalho Tardif (2008, p. 269) destaca [...] "os saberes como temporais, plurais e heterogêneos, personalizados e situados, e que carregam consigo as marcas do seu objeto, que é o ser humano". Eles se articulam e se mobilizam durante sua prática pedagógica, então, relaciona-se com a época e a sociedade na qual está inserido, além de experiências, história de vida e carreiras singulares.

Ainda, segundo Tardif (2002, p. 36) o saber docente, assim como outros saberes é "[...] um saber plural, formado pelo amálgama, mais ou menos coerente, de saberes oriundos da formação profissional e de saberes disciplinares, curriculares e experienciais". Esses saberes os professores precisam dominar, integrar e mobilizar na prática docente. Diante dessa realidade enquanto idealizador do termo epistemologia da prática profissional, Tardif (2002, p.255) a conceitua como o "estudo 
do conjunto dos saberes utilizado realmente pelos profissionais em seu espaço de trabalho cotidiano para desempenhar todas as suas tarefas".

Nesse sentido, para uma formação continuada de qualidade além dos saberes já citados para a prática profissional docente são fundamentais segundo Nóvoa (1991) outros três aspectos: pessoal, profissional e organizacional. Pessoal (formação críticoreflexiva), profissional que é a profissão docente (identidade), e organizacional (para que ocorram inovações é preciso transformações na organização escolar).

Nesse sentido:

[...] a formação deve estimular uma perspectiva crítico-reflexiva, que forneça aos professores os meios de um pensamento autônomo e que facilite as dinâmicas de autoformação participada. Estar em formação implica um investimento pessoal, um trabalho livre e criativo sobre os percursos e os projetos próprios, com vistas à construção de uma identidade, que é também uma identidade profissional. [...] urge por isso (re) encontrar espaços de interação entre as dimensões pessoais e profissionais, permitindo aos professores apropriar-se dos seus processos de formação e dar-Ihes um sentido no quadro das suas histórias de vida. (NÓVOA 1995, p. 25).

É fundamental que ocorra essa articulação entre formação inicial e continuada para isso a escola precisa de formas flexíveis, inovadoras e críticas. Além dessa relação, a escola deve ter a práxis em seu meio, ou seja, momentos de ação-reflexão-ação, onde seus profissionais devem estar em constante processo de atualização acompanhando a demanda que hoje a sociedade exige. (FREIRE,1 996).

Assim, defendemos a proposta de que a formação continuada deve se dar com base na realidade da própria escola, em suas reais necessidades e seu projeto pedagógico. Não se pode pensar a perspectiva de uma nova escola sem colocar como meta primordial a 
formação continuada. Para tanto, é necessário que a escola se constitua num espaço de crescimento do professor. (SILVA, 2002, p.15).

Desse modo, se faz necessário uma fundamentação teórica para orientar a ação reflexiva. Pimenta (2002, p. 26) aponta que o "papel da teoria é oferecer aos professores perspectivas de análise para compreenderem os contextos históricos, sociais, culturais, organizacionais e de si mesmos como profissionais, nos quais se dá sua atividade docente, para neles intervir, transformando-os". Pimenta (2012) afirma a necessidade da teoria e prática andarem sempre juntas em processos de formação continuada:

O autor aponta que o:

[...] o saber docente não é formado apenas da prática, sendo também nutrido pelas teorias da educação. Dessa forma, a teoria tem importância fundamental na formação dos docentes, pois dota os sujeitos de variados pontos de vista para uma ação contextualizada, oferecendo perspectivas de análise para que os professores compreendam os contextos históricos, sociais, culturais, organizacionais e de si próprios como profissionais. (PIMENTA 2012, p. 28)

Diante dessa realidade, a prática reflexiva na profissão docente é um movimento para rever as práticas, é pertinente considerar a reflexão necessária ao exercício da prática pedagógica, para que se possa obter um entendimento claro da prática desenvolvida por cada professor, visando chegar a uma verdadeira prática reflexiva como afirma (PERROUND, 2002, p. 13) "a reflexão que permeia a concepção do professor reflexivo é uma reflexão permanente e contínua, que permite ao professor por ela envolvido, compreender as ações por ele desenvolvidas, analisa-las e, caso seja necessário, reconstruí-las".

Dessa forma, a reflexão crítica permanente deve constituir-se como orientação prioritária para a formação continuada dos professores que buscam a transformação através de sua prática educativa: 
A prática docente crítica, implicante do pensar certo, envolve o movimento dinâmico, dialético, entre o fazer e o pensar sobre o fazer. [...] O que se precisa é possibilitar, que, voltando-se sobre si mesma, através da reflexão sobre a prática, a curiosidade ingênua, percebendose como tal, se vá tornando crítica. [...] A prática docente crítica, implicante do pensar certo, envolve o movimento dinâmico, dialético, entre o fazer e o pensar sobre o fazer (FREIRE, 1996 p. 38).

Entretanto o mesmo autor escreve que "[...] o importante é que a reflexão seja um instrumento dinamizador entre teoria e prática". Freire (1996, p. 39). Por isso, não basta apenas pensar e refletir, é fundamental que tal reflexão leve o profissional a uma ação transformadora, fazendo-o pensar sobre seus desejos, vontades, histórias.

Portanto ser professor hoje exige o desenvolvimento de uma complexidade de tarefas. Os principais desafios que o profissional docente enfrenta é o de manter-se atualizado e desenvolver práticas pedagógicas eficientes. Hoje, os professores têm que lidar não só com alguns saberes, como no passado, mas também com a tecnologia e com a complexidade social (NÓVOA, 1992). Para transformar informação em conhecimento o professor precisa da inteligência que é a capacidade de projetar cenários de valores, conhecimento "matéria-prima" para a realização de qualquer projeto, teoria, compreensão que é a ação do professor, informação veículos de comunicação e bancos de dados que é o conhecimento acumulado no decorrer da vida profissional com pessoal. (MACHADO, 2000).

\section{CONSIDERAÇÕES FINAIS}

Transformar informação em conhecimento pela escola é muito relevante para sociedade contemporânea, devido a forte característica da competitividade, do mundo globalizado, o ensino contribui para a formação e transformação da sociedade. As funções da escola, os saberes docentes são essenciais para a construção do sujeito, futuro profissional que busca o conhecimento, mas esse papel é melhor desempenhado quando existe um esforço do próprio educando, 
Para atender a essa demanda a escola precisa ser um espaço de mudança, de novos processos de aprendizagem baseados na criatividade, no desenvolvimento de competências, nas atitudes, nos valores, na estruturação de novas aptidões necessárias para viver e trabalhar no mundo globalizado, bem como orientá-los para a vida. A escola precisa formar cidadãos e pessoas, capazes de participar ativamente na construção e melhoria da sociedade promovendo o desenvolvimento das capacidades de aprender a conhecer, através do exercício autônomo, de processos e habilidades cognitivas, sendo um espaço de construção e apropriação do conhecimento de forma interativa e colaborativa.

Nesse sentido, o professor reflexivo precisa ser um orientador criando condições na concretização das aprendizagens e na construção dos conhecimentos dos alunos. Para isso, os docentes precisam da formação inicial e continuada que é fonte de saberes, dos saberes disciplinares, curriculares, experienciais, que forma os profissionais, da formação acadêmica que são úteis e necessários, dos conhecimentos adquiridos no decorrer do exercício docente, dos cursos de especialização e aprimoramento profissional, e da troca de experiências entre os professores. Portanto os docentes precisam ter uma formação integral que abranja conhecimento, habilidades, atitudes e valores, saber lidar com todos os tipos de mudanças, serem facilitadores, comunicadores e pilares desta transformação no ensino.

O aluno, por sua vez é sujeito central para efetivar o ensino de qualidade deve questionar pesquisar, o sujeito não se forma a partir de conteúdo, e sim por meio de desafios que o aprendizado propõe. Por isso precisam trazer exemplos do dia a dia, pensar o que vem em termos de mundo, quais as competências, os desafios, como estudantes, buscar novas estratégias na forma de pensar, sistematizar, escrever, construir, desenvolver esse conhecimento.

Os sujeitos, autores necessitam de uma ruptura do comum na área do ensino, precisa de inovação, rapidez na tecnologia, na tomada de decisões, no desejo de aprender, e pela necessidade de fazer diferente, assumindo novas responsabilidades, 
aprendendo novas habilidades conceituais, técnicas e humanas para saber lidar com a equipe de trabalho.

Portanto os aspectos que favorecem a transformação de informação em conhecimento na escola, desde que ocorra uma formação docente na e para a complexidade do mundo globalizado são, por exemplo: conhecimentos prévios, significado a informação, dialogo, criatividade, contextualização, realidade do aluno, respeita as características individuais, compreender o mundo, os quatros pilares da educação: aprender a conhecer, aprender a fazer, aprender a conviver e aprender a ser.

\section{REFERÊNCIAS}

ALTET, Marguerite. As competências do professor profissional: entre conhecimentos, esquemas de ação e adaptação, saber analisar. -2. ed. rev. - Porto Alegre: Artmed, 2001.

ANTUNES, Celso. Como desenvolver competências em sala de aula, ed. Vozes. Petrópolis. 2001.

. A Prática dos Quatros Pilares da Educação na sala de aula; fascículo 17 Petrópolis Rio de Janeiro: Vozes 2010, - (coleção sala de aula).

CHIAVENATO, Idalberto. Idalberto. Administração de Recursos Humanos: Fundamentos básicos: 5 edição. São Paulo: Atlas AS, 2003.

CANDAU, Vera Maria. A formação continuada de professores: tendências atuais. In: REALI, Aline de M. R.; MIZUKAMI, M. da G. N. (Orgs). Formação de professores: tendências atuais: São Carlos: EDUFSCar, 1996.

CARDOSO, Celso Aparecido. Formação crítico-reflexiva: a relação teoria e prática. Integração: ensino, pesquisa, extensão, ano VIII, № 30, agosto de 2012. 
DELORS, Jacques et al. EDUCAÇÃO: um tesouro a descobrir. 5. ed. São Paulo: Cortez, 2001.

A educação para o século XXI: questões e perspectivas. Porto Alegre. Artmed. 2005.

. um tesouro a descobrir. Relatório para a UNESCO da Comissão Internacional sobre Educação para o Século XXI. 4 ed. São Paulo: Cortez, 2000.

. (org.). Educação um tesouro a descobrir - Relatório para a Unesco da Comissão Internacional sobre Educação para o Século XXI. Editora Cortez, $7^{a}$ edição, 2012.

DEWEY, John. Democracia e Educação. São Paulo: Nacional, 1979.

Disponível em: < https:/www.gramatica.net.br/origem...palavras/etimologia-deconhecime... Acesso em 14/11/2016.

Disponível em: < https://www.dicionarioetimologico.com.br/informacao/>. Acesso em 14/11/2016.

FERREIRA, Aurélio B. H. O dicionário da língua portuguesa. Rio de Janeiro. Editora Nova Fronteira, 1999.

FREIRE, Paulo. Pedagogia da autonomia: saberes necessários à prática educativa. São Paulo: Paz e Terra, 1996.

GADOTTI, Moacir. Boniteza de um sonho: ensinar-e-aprender com sentido. 2ed. São Paulo: Instituto Paulo Freire, 2011.

LIBÂNEO, JOSE, CARLOS. Organização e gestão da escola: teoria e prática. 5. ed. revista e ampliada-Goiânia: MF livros, 2008

Adeus professor, adeus professora? Novas exigências educacionais e profissão docente. 5. ed. São Paulo: Cortez, 2001. 
. ET. AL.(Coord). Os professores e a sua formação. 2. ed. Lisboa: Dom Quixote, 1995. . (org.) Os professores e sua formação. Lisboa: DOM Quixote, 1992.

LÉVY, Pierre. As Tecnologias da Inteligência: o futuro do pensamento na era da informática. Rio de Janeiro: Ed. 34, 1993.

LIBERALI, F. C. Formação crítica de educadores: questões fundamentais. Campinas: Pontes, 2010.

LUCKESI, C. C. e PASSOS, E.S. Introdução à filosofia: aprendendo a pensar. São Paulo: Cortez, 1996.

MATURANA, Humberto r. \& Varela, Francisco j. a árvore do conhecimento. athena: palas, 2001.

MACHADO, Nilson. José. - Educação: projetos e valores. São Paulo: Escrituras, 2000.

NÓVOA, Antonio. A formação contínua de professores: realidades e perspectivas. Aveiro: Universidade de Aveiro, 1991.

OLIVEIRA, João Ferreira, FONSECA, Marília e TOSCHI, Mirza. Educação, gestão e organização escolar: concepções e tendências atuais. In: OLIVEIRA, João Ferreira (org.) Escolas gerenciais: planos de desenvolvimento e projetos políticospedagógicos em debate. Goiânia: UCG, 2004a.

OLIVEIRA, Valeska Fortes. Imagem de Professor: Significações do Trabalho Docente. 2. ed. ljuí: Ed. Unijuí, (coleção educação). 2004b.

PAIN Sara. Diagnóstico e tratamento dos problemas de aprendizagem. Porto Alegre: Artes Médias, 1985. 
PERRENOUD, Philippe et al. As competências para ensinar no século XXI: a formação dos professores e o desafio da avaliação. Tradução Claudia Schilling e Fátima Murad. Porto Alegre: Artmed, 2002a.

A prática reflexiva no ofício do professor: Profissionalização e Razão Pedagógica. Porto Alegre: Artmed, 2002b.

. Dez novas competências para ensinar. Porto Alegre, artmed, 2000.

- Práticas pedagógicas, formação docente e formação: perspectivas sociológicas. Lisboa: Dom Quixote/IIE, 1993.

Formar Professores em Contextos Sociais em Mudanças. Prática Reflexiva e Participação Crítica. Porto Alegre artemed, 1999a.

. Construir as Competências desde a Escola. Porto Alegre: Artes Médicas, 1999b.

PIMENTA, S. G. (Org.). Saberes pedagógicos e atividade docente. São Paulo: Cortes, 1999.

. O Estágio na Formação de Professores - Teoria e Prática. 11르 Ed. São Paulo: Cortez, 2012. . Professor reflexivo: construindo uma crítica. In: PIMENTA, S.; GHEDIN, E. (Org.). Professor Reflexivo no Brasil: gênese e crítica de um conceito. 2. ed. São Paulo: Cortez, 2002.

SAVIANI, D. Pedagogia histórico-crítica. 8. ed. Campinas: Autores associados, 2003.

SILVA, Moacyr da. A formação do professor centrada na escola: uma introdução. São Paulo: EDUC, 2002. 
TARDIF, Maurice. Saberes docentes e formação profissional. 2. ed. Petrópolis: Vozes, Rio de Janeiro, 2002.

Organização e Gestão da Escola: Teoria e prática. 5‥ ed. Revista e Ampliada - Goiânia : MF livros, 2008.

TEDESCO, Juan Carlos. O novo pacto educativo: educação, competitividade e cidadania na sociedade moderna. São Paulo: Ática, 1998.

O novo pacto educativo. São Paulo: Ática, 2001.

VERGARA, Sylvia Constant. Gestão de Pessoas: São Paulo. Atlas, 2ª tiragem; 2000.

YOUNG, Michael. Para que servem as escolas? In: Educ.soc, Campinas, vol. 28 ser/dez. 2007.

2. Trabalho de Conclusão do Curso de Pós-Graduação em Espaço Alternativo do Ensino e da Aprendizagem.

3. Aluna do Curso de Pós-Graduação em Espaço Alternativo do Ensino e da Aprendizagem, Graduada em Administração pela UNIJUÍ e Pós-Graduada em Gestão Administrativa na Educação pela ESAB, é estudante admjaneteroppa@gmail.com.

Enviado: Outubro, 2019.

Aprovado: Março, 2020. 